\title{
Reporting student progress: What might it look like?
}

\author{
Hilary Hollingsworth \\ Australian Council for Educational Research \\ Jonathan Heard \\ Australian Council for Educational Research
}

Anthony Hockey

Principal, St Mary's Primary School

Tegan Knuckey

Assistant Principal, Balwyn High School

https://doi.org/10.37517/978-1-74286-638-3_16

Hilary Hollingsworth is a Principal Research Fellow in the Educational Monitoring and Research Division at ACER. She has 30 years of experience working in a wide range of national and international educational contexts including schools, universities, research organisations, government education departments and private education service organisations. Her expertise is in teaching and learning, teacher education and professional development, classroom observation frameworks and the use of video, teacher feedback, teaching quality, assessing student learning and communicating student progress. Hilary is a member of ACER's Centre for Assessment Reform and Innovation (CARI) and led the Communicating Student Learning Progress project.

Jonathan Heard is also a Research Fellow in the Educational Monitoring and Research Division at ACER. He has 15 years' experience as a high school teacher, holding leading teacher positions in institutional coaching and pedagogy. His current work foci at ACER include the assessment of general capabilities and critical thinking, and researching teaching and learning initiatives in school education. Jonathan is also a member of CARI and was a key researcher in the Communicating Student Learning Progress project.

\section{Abstract}

The Communicating Student Learning Progress review produced by ACER in 2019 set out recommendations for schools and systems to improve the way schools report on student learning, in particular learning progress. Two case study schools from Victoria - a Catholic primary school and government secondary school - discuss changes they've made to their student reporting processes, in response to the review's recommendations. Further research is recommended into how schools are rethinking reporting to engage students and parents in monitoring learning growth.

\section{Introduction}

In 2019, a review of student reporting in Australian schools was published as the culmination of a research project undertaken by a small team funded internally through the Australian Council for Educational Research (ACER) Centre for Assessment Reform and Innovation (CARI). Titled Communicating Student Learning Progress (Hollingsworth et al., 2019), the review sought to understand the extent to which reporting practices in Australian schools met the stated aim of communicating both achievement and progress (Australian Education Regulation, 2013), with 'progress' understood as a student's gain, growth or increasing proficiency along a continuum of learning as measured over time. 
One outcome of the project was a set of eight recommendations to schools and systems about how student reporting might more successfully achieve the goal of communicating the progress students make in their learning, as well as their performance in subjects and assessments. An abridged version of these recommendations is contained in Figure 1.

\section{Figure 1 Recommendations for communicating student learning}

1. Schools and systems should use consistent terminology to communicate about student learning.

2. Student reporting should be continuous and aligned to the assessment cycle.

3. Student reporting should explicitly represent and communicate learning progress.

4. Student reporting should explicitly communicate student learning against expectations.

5. Student reporting should clearly articulate how performance ratings are defined.

6. Student reporting should present information that is accessible and provides different levels of detail.

7. Student reporting should include specific directions for future learning.

8. Methods used to communicate student learning should have distinct but complementary purposes.

In addition to these recommendations to schools, the project team proposed recommendations for future research, including to identify and investigate work being undertaken in schools on the design and use of reporting formats that better support, monitor and represent student progress. The aim of such research would be to determine what is possible to achieve and what 'works', for teachers, parents and students.

Nearly two years on from the publication of the report, several questions relevant to this potential research direction have emerged:

- How are schools making use of these recommendations?

- What changes have schools made to their reporting processes?

- What have been the effects of these changes and what have been the challenges?

This paper seeks to explore these questions by presenting the recent work of two schools in Melbourne - St Mary's Primary School, Williamstown and Balwyn High School - and their efforts to reform aspects of their student reporting systems.

Both schools are focusing on the ultimate goal of more effectively communicating learning progress in reports, with the view to making reporting more meaningful for students and parents. To this end, they are both aiming to address recommendation 3 outlined in Figure 1. However, they were asked to describe which of the other recommendations they have focused their attention on in their efforts to make improvements, and what the results have been thus far.

\section{Towards making more effective comments related to progress

\author{
- Anthony Hockey, Principal, St Mary's Primary School, Williamstown
}

\section{Which of the eight recommendations from the Communicating Student Learning Progress report were you most interested to address? Why?}

It is a matter of taking small steps. Our main objective was to work towards making our report comments more effective, so our initial focus was on recommendations 1, 3 and 4 .

What we found was that our school reports were very traditional in that they tended to report on student achievements. The reports listed things the student had been working on and provided 
a sentence at the start or finish of the comment that let parents know how well the student had achieved in the area. For example, 'Student A has a good understanding of place value to two decimal places'. What the parents did not know from this is what the student knew beforehand, so was this good progress, below the expected level of growth, or was it in fact excellent progress?

Quite often the parent did not fully understand the reference to the curriculum standard or the teacher terminology. Feedback from the parents suggested there was too much 'teacher talk' and that they did not really understand what was happening with their child after reading the comments. Parents were also telling us that our comments were way too long.

What we wanted was effective comments that told parents about the progress their child was making.

\section{What changes did you make?}

We made two significant changes. First, we created the opportunity for more student voice in the school reports. Students in Years 3 to 6 now input directly into their school report. Students give themselves a mark using the same rubrics as the teachers and their self-assessment marks appear next to the teacher's. This year we have expanded the scope of student input in their reports: the students are also going to write their own comment that will appear next to the teacher's.

Second, we changed the structure of how the comments are written. In our Literacy and Numeracy comments, we found we were listing a whole lot of what we had taught and used a lot of teacher jargon, but parents were not learning what they really wanted to know. We have simplified the comment to answer questions like, what is something the student did well in, what is something they are still struggling with, what steps do they need to take to improve? Our aim is for our comments to become shorter but more effective.

\section{What changes have you seen as a result?}

Some of our changes have been obvious - our students self-assess in grades 3 to 6 , and in the upcoming reports they will self-comment. On the whole the teacher comments are shorter, however some teachers still want to write lengthy comments.

The biggest change relates to simplifying how comments are written. Some staff have really taken on the idea that they are telling the journey of a student's learning rather than the end point. Their comments talk more of what they can do now, compared to what they were doing previously, so the parent can see the progress made. For some teachers it was simply adding the word 'now', that changed their thinking. What can the student do now that they previously could not?

Our work in this area also led us to include students in the parent-teacher interview, something that had not been done in the school previously. This has meant that the students are gaining greater understanding of their own learning needs.

\section{What challenges did you encounter, or what is still a challenge?}

The challenge we have come across is shifting the philosophy of staff members who have written reports the same way for many years. We would not say our comments are perfect and we are still having teachers struggling to change how they have written reports. Our teachers who have been teaching for longer are the ones finding the change the hardest. Their fear appears to be breaking away from listing what they have been teaching, it is as if they feel they need to write all this to prove to the parent community that they have taught something. Comments like 'Our parents expect to see a long comment', or 'Our parents will not be happy' come from the ones who are struggling the most to change. 


\title{
Towards presenting information that is accessible and focused on future learning \\ - Tegan Knuckey, Assistant Principal, Balwyn High School
}

\author{
Which of the eight recommendations from the Communicating Student Learning \\ Progress report were you most interested to address? Why?
}

In our work at Balwyn High School rethinking our reporting practices, we read and considered all the recommendations, however two in particular - recommendations 6 and 7 - emerged as priorities.

In terms of recommendation 6 , feedback received from our parents was that information we reported was not always accessible. Parents felt that the comments made by teachers on Common Assessment Tasks (CATs), which were reported as part of our continuous reporting cycle, were too 'task specific' or 'jargony' for them to be able to understand. Beyond Year 7, parents said they did not engage much with comments in continuous reports, and quantitative data from our school management system (Compass) indicated that parents did not frequently access semester reports.

In regard to recommendation 7, whilst the comments associated with a student's performance on CATs indicated how the student could improve, they often pertained specifically to improvement in the task just completed and, therefore, were not necessarily transferable to future tasks in the subject. As a result, parents did not feel that the comments supported them to support their child's learning.

Parents also indicated that they were most interested in how their child presented in class - Did they work hard? Did they ask questions? Did they contribute? Were they organised? There is often a (perceived) correlation between 'learning behaviours' and student learning progress and our parents really wanted to know what their child was like in class, believing this information could support them to help their child improve. The 'effort' and 'behaviour' judgements we were making, by contrast, were considered too superficial to provide much guidance.

To aid us, and students and parents, in understanding what the next steps of future learning might be for a learner, we developed learning continua for each subject. While based upon the Victorian Curriculum achievement standards, these continua more readily suggested what a student might need to work on next in order to develop greater mastery of key skills and knowledge that run through the curriculum right up to VCE.

\section{What changes did you make?}

We wanted students to value learning and use every opportunity to demonstrate what they were able to do so they could make progress in their learning. Our previous assessment and reporting system that placed value solely on three large assessments per subject each semester did not enable this. Therefore, we removed CATs from the vernacular and from semester reports, implementing a system that reflected that every lesson every day was an opportunity for students to show what they know and can do. Instead of continuous reporting to parents on CATs, we now complete and distribute 'Reporting Points' twice per semester (and a semester report at the end of each semester).

Reporting Points are similar in appearance to semester reports in that there is one page per subject. On this page is a generic comment regarding what Victorian Curriculum strands/sub-strands have been covered in the period, an individual comment regarding how the students can continue to make learning progress in the subject, and learner profile judgements (based on statements aligned with our school's shared learning norms). 


\section{What changes have you seen as a result?}

Many students are more engaged in more classes, knowing that everything they do is valued. They are starting to understand their role in the formative assessment processes being used. Students are also less anxious about assessment, knowing they are provided multiple opportunities to demonstrate their knowledge and skills, and that being able to demonstrate these under timed conditions is not the 'be all and end all'.

Parent feedback suggests that the Reporting Point document allows them to see patterns in how their child approaches learning so they can have productive conversations at home about how to move forward.

\section{What challenges did you encounter, or what is still a challenge?}

Constructing and trialling the use of the learning continua we developed, amid all of the other dayto-day tasks that leaders and teachers need to engage in, required intentional investment and strong distributed leadership.

Some teachers are still clinging to the concept of CATs and are not providing their students with as much feedback along the learning journey as other teachers.

Teachers' ability to use technology for pedagogy, assessment and reporting has been a strong professional learning focus, with the 2020 period of remote learning being an important catalyst for a lot of the growth in this area. However, there are still large gaps in the competence of teachers in this area.

The reporting platform we use, Compass Continuum, is still a little clunky (though improving) and does not visually represent progress in a way that is obvious or explicit for parents - they need to hover over data points and know how to use the program in order to more fully access the information available.

\section{Conclusion}

The perspective of these two schools suggests there is a wider acknowledgement that reporting can be a valuable instrument to engage parents and students more in the learning process. The challenges they describe point to some significant and complex issues associated with reorienting the purpose of reporting away from being a retrospective summary of achievement, and changing associated long-held practices.

It remains an area of research interest to continue to identify schools, systems and providers who are engaged in reporting reform and who are reimagining what communicating to parents about their child's learning might look like; to capture their practice and identify what works for whom and why.

Anthony Hockey is the Principal of St Mary's Primary School in Williamstown, Victoria. Tegan Knuckey is Assistant Principal at Balwyn High School in Victoria.

\section{References}

Australian Education Regulation. (2013). https://www.legislation.gov.au/Details/F2019C00086

Hollingsworth, H., Heard, J., \& Weldon, P. (2019). Communicating student learning progress: A review of student reporting in Australia. ACER. 